Bulletin of Electrical Engineering and Informatics

Vol. 11, No. 1, February 2022, pp. 29 41

ISSN: 2302-9285, DOI: 10.11591/eei.v11i1.3338

\title{
Smart irrigation system with photovoltaic supply
}

\author{
Elia Erwani Hassan¹, Leong Lek Chung', Mohamad Fani Sulaima', Nazrulazhar Bahaman², Aida \\ Fazliana Abdul Kadir ${ }^{1}$ \\ ${ }^{1}$ Energy and Power System, Faculty of Electrical Engineering, Universiti Teknikal Malaysia Melaka, Malaysia \\ ${ }^{2}$ Information Security Forensics and Computer Networking, Faculty of Information and Communication Technology, Universiti \\ Teknikal Malaysia Melaka, Malaysia
}

\begin{tabular}{|c|c|}
\hline Article Info & ABSTRACT \\
\hline Article history: & \multirow{10}{*}{$\begin{array}{l}\text { Maximizing crop yielding is an extensive problem faced by the population in } \\
\text { a country. The main issue comes from the farmer who still implemented the } \\
\text { conventional method of irrigation that required human actions, especially for } \\
\text { water pump operation. As an alternative, the automatic solution becomes a } \\
\text { demand with the internet of things (IoT) support system to overcome the } \\
\text { agriculture scenario. Meanwhile, multiple sensors controlled by the ESP32 } \\
\text { microcontroller are also used to measure the crucial parameters that } \\
\text { influenced the living conditions of crops and are called input parameters. } \\
\text { Meanwhile, the implementation of a fuzzy logic controller is to control the } \\
\text { timing of water volume based on the inputs data obtained through the sensors' } \\
\text { responses. Solar energy is the main supply because of the zero-cost expense } \\
\text { and environmentally friendly energy generation. In large, this research } \\
\text { developed the smart irrigation system (SIS) with photovoltaic (PV) panels as } \\
\text { a supply to sustain the energy required for empowering the entire process. As } \\
\text { a result, the SIS is found as a successful system in controlling the best suitable } \\
\text { time of water irrigation. The soil evaporation contents obtained from the } \\
\text { experiment were also close to actual accurate data reference for Melaka state } \\
\text { to verify the solution. }\end{array}$} \\
\hline Received Aug 16, 2021 & \\
\hline Revised Oct 26, 2021 & \\
\hline Accepted Jan 6, 2022 & \\
\hline keywords: & \\
\hline Fuzzy logic & \\
\hline Internet of thing & \\
\hline Photovoltaic & \\
\hline Solar system & \\
\hline Watering system & \\
\hline
\end{tabular}

This is an open access article under the CC BY-SA license.

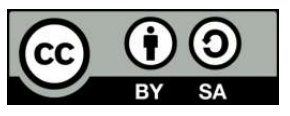

\section{Corresponding Author:}

Elia Erwani Hassan

Energy and Power System (EPS), Faculty of Electrical Engineering, Universiti Teknikal Malaysia Melaka

Jalan Hang Tuah Jaya,76100 Durian Tunggal, Melaka, Malaysia

Email: erwani@utem.edu.my

\section{INTRODUCTION}

This project introduces an irrigation system that is integrated with sensors technology aimed at a better amount of plantation yields. Typically, a farmer will spend plenty of time irrigating their crops at a particular time like early in the morning or evening. However, during irrigation tasks, some details like soil moisture or air humidity are not considered to optimize the water supply [1], [2]. Since the irrigation system relates to technology devices thus it would require electrical energy to operate. Today electrical spending is getting expensive besides there is a considerable percentage of electrical energy needs for some conventional fuels like fossil fuel, coal, natural gas or others which then caused the sources to become depleted [3]. Therefore, using a photovoltaic (PV) system supply is encouraging because the energy is obtained directly propositional from the amount of light irradiance. An advantage of PV is because the system manages to convert solar energy into electric power. As a result, the PV energy presented will act as the main supply to keep the water pump and sensors working well [4].

The PV system must generally consist of a solar panel, voltage stabilizer, and power inverter to function [5]. The PV panel would produce direct current and direct voltage during the initial phase. However, the voltage rating of the load circuit will not be the same as that produced by the PV panel. Hence, a power 
converter is responsible for rectifying the voltage amplitude to meet the demand needed by electronic circuit load [6]. As an action, this research proposed the pulse width modulation (PWM) charge controller to play an essential role as a converter model. The PWM controller circuit used two MOSFETs to control the charging current that flows into the energy storage tank. The task for the MOSFETs is to produce a different level of charging rate which becomes a switch by manipulating the sign controller transmission to its gate terminal. The signal frequency of the gate terminal can be easily controlled by a microcontroller or other discrete electronic components. In the next phase, a comparator is compulsory in comparing the voltage of both solar panels and energy storage tanks [7]. The comparator will then determine the suitable PWM signal ratio that needs to feed into the MOSFET.

The performance of the photovoltaic panel is sensitive to solar radiation, ambient temperature, and humidity [8]. Therefore, the generation of voltage and current can be varied from time to time. The fluctuation of electrical energy can trigger several electrical failures like overcurrent, Undervoltage or electrical harmonics [9]. Therefore, a voltage stabilizer is compulsory to relate to a photovoltaic panel instead of plug directly into the load. The voltage stabilizer provides constant voltage and limits current to protect the electronic gadget from any damage [10].

Irrigation is developed through artificial applications to deliver water to crops through different types of distribution lines like hoses, pumps, sprays, and tubes. Consequently, the large scale of irrigation would bring up the environmental pollution. The most common scenario is soil erosion that will endanger the structure crops while dropping the yield amount. As a result, many types of irrigation systems are improved to mitigate the impact of irrigation on the environment [11]. Whereas furrow irrigation is known as a channel of watering by gravity or in other words, the water is not evenly spread throughout the field [12]. The problem occurred when a large stream of furrow irrigation erodes the soil while a small stream only allows flowing water in a short distance. Therefore, the limitation for flowing water is required to meet uniform irrigation the system. The distance of water flow can be controlled by adjusting the burrow's slope to avoid the soil from eroding rapidly.

Accordingly, several impacts were brought by irrigation toward the environment, classified by the long and short-term effects [13]. Generally, the negative impact is significant as it increases over time even though water is suitable for a plant to moisture its surrounding soil. In addition, it would lessen the soil strength when excessive amounts of water are poured into the ground [14]. As known, traditional irrigation activity will waste a lot of water resources to irrigate the crops. Besides that, most farmers had a habit of watering their crops at a particular time regardless of weather conditions. Even though during the rainy season, farmers yet carry out the same routine to move around the field for irrigation, pesticide, and weeding work. However, with the support of modern technology, the routine will not necessarily be done daily.

From earlier research, there are a few vital parameters that needed to be considered by farmers like weather forecast, air humidity, ambient temperature, and soil moisture [15]. In addition, the internet of things (IoT) has become a critical ideology to perform networking that can interconnect anything through the internet. The implementation of IoT requires a lot of essential devices to allow communication using the IoT platform successful. As reported, many types of IoT platforms can be accessed through Wi-Fi, local area network (LAN), general packet radio service (GPRS), and other network connectivity methods [16].

As an advantage, the implementation of IoT in agriculture can resolve the issue of water resources usage efficiency and environmental pollution. Thus, an excessive improvement will be achieved when the farmer transforms their traditional farming activity into a modern approach. The beneficial due to the modern implementation were reported by research which highlighted that the productivity of crop yield had increased from the implementation of IoT [17]. As reported, there is no specific temperature and humidity value that is suitable for all types of plants. For that reason, the optimum range of temperature and humidity sensors could be controlled using sensors [18]. This is also called essential real-time monitoring, handling, and analysis of crops for a better quality of growth.

Furthermore, to make modern farming more efficient, an intelligent fuzzy logic controller is required in the system development. A fuzzy logic controller has numerous membership rule sets to determine the truth value between 0 and 1 [19]. Consequently, the fuzzy logic helps control the watering system's valve by controlling the amount of water distributed to the crops using the setting membership rules. Therefore, the features of the fuzzy logic-based irrigation system will respond to maintain a water resource-saving and reduces water stress in soil. At the same time, several significant input parameters to identify the amount of water resource to crops are soil moisture, temperature, air humidity, or others [20]. Accordingly, this research is focused on the smart irrigation system (SIS) with the integration of IoT systems. In principle, the photovoltaic (PV) panel is used to supply energy for the whole irrigation process to meet the green environmental energy solution. Hence, the pulse width modulation (PWM) controller is introduced as the switch for the PV controller circuit. The SIS development consists of numerous sensors to monitor the data required to measure the suitable water volume for irrigation. All data observed will be stored in google form through the IoT support system.

Bulletin of Electr Eng \& Inf, Vol. 11, No. 1, February 2022: 29-41 
In the system, the fuzzy logic membership functions help control the necessary amount of water from the input data parameters such as soil moisture, temperature, air humidity from the sensors data reported. Throughout the experiment, the SIS worked appropriately as what was programmed. Besides, the result of evaporation soil content during the irrigation process obtained was close to the actual data content as reference. From the result, the SIS has shown the best performance and is recommended to deploy in large-scale crops.

\section{RESEARCH METHOD}

In general. the design for the PWM solar charge controller's design for the SIS development is presented in Figure 1. The basic function of the PWM charge controller is to regulate the coming input voltage that will be received at the solar panel. Normally, the gained input direct solar voltage is fluctuated due to atmospheric temperature, shading, sunlight intensity, etc. The key performance of the solar panel mostly depends on the irradiance factor from sunlight. Meanwhile, when irradiance increase makes the current to be increased proportionally. As a result, the output voltage will increase marginally up to the level of the maximum open-circuit voltage. Besides that, if a cloud shade above the solar panel occurs, it will cause a substantial power output drop. The increment in temperature of the solar panel surface will also result in the output voltage reduction significantly.

During the experiment, the possible maximum voltage and maximum current generated from the capacity solar module applied are $21.24 \mathrm{~V}$ and $1.88 \mathrm{~A}$ respectively. Hence, the task of the solar charge controller is to regulate the maximum power rating to satisfy the design criteria.

Initially, the PWM technique as in Figure 1 is technically utilized for lower average power delivery by periodically chopping the power transfer. This PWM solar charge controller controls pulse width modulation amount by using an Arduino Nano microcontroller. The Arduino Nano type of microcontroller has a high switching frequency of pulse width modulation in the implementation. Since the high frequency of switching PWM will result in increased power of loss, thus the frequency received by the microcontroller will be tuned down. Then, the PWM signal is used to control the switching gate of MOSFET to enable battery charging. During the circuit operation, the frequency of the Arduino Nano microcontroller was reduced from the original frequency of $16 \mathrm{MHz}$ to only $61 \mathrm{~Hz}$.

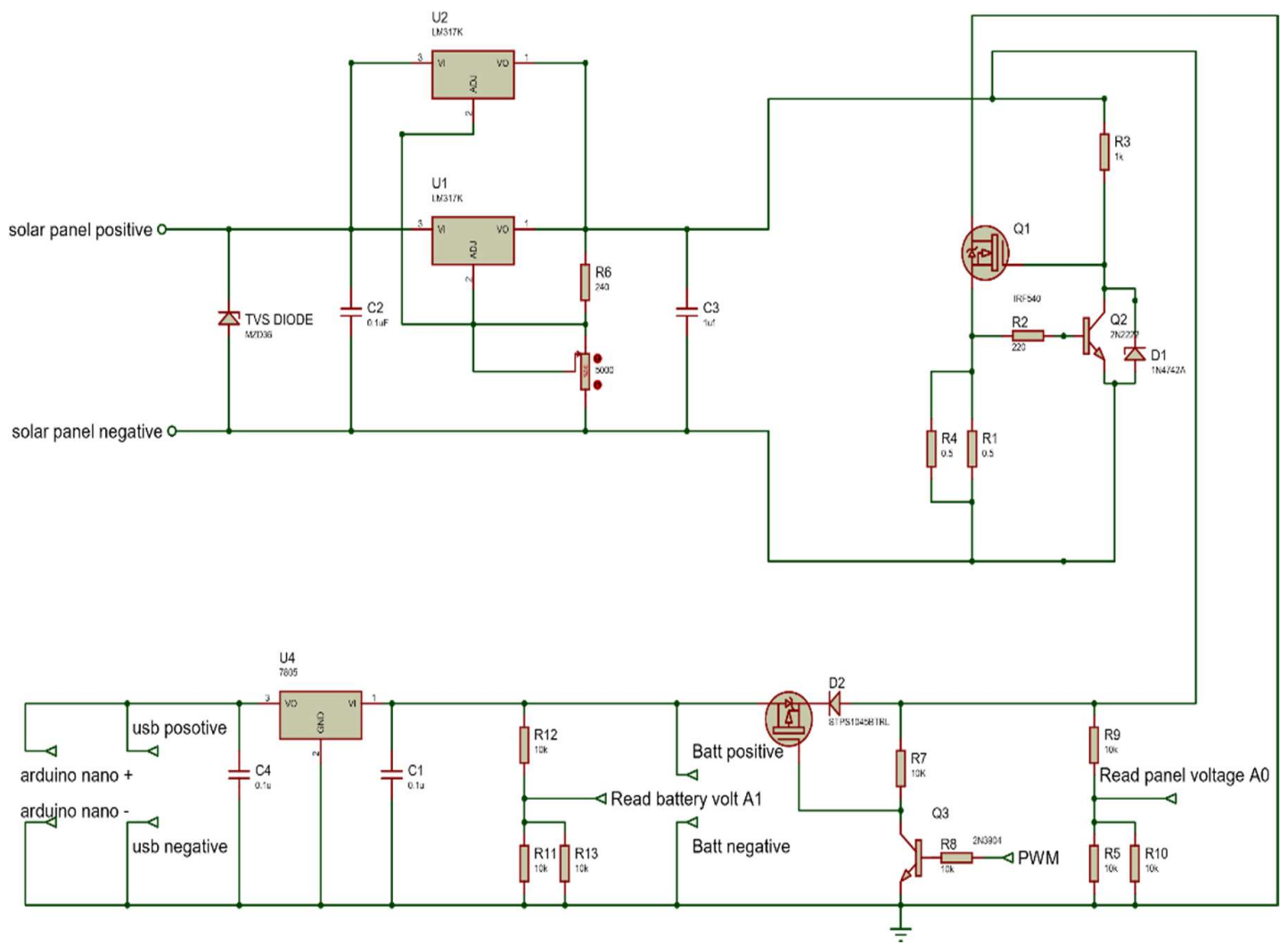

Figure 1. PWM charge controller design 
A battery acts as a storage of energy needed to power up the SIS system and sustain the operation of the solar charge controller. Furthermore, the total energy demand from the watering system relies fully on the battery used. Therefore, the battery with a rated capacity of $12 \mathrm{~V}, 700 \mathrm{mAH}$ is chosen to realize the task. Furthermore, this $12 \mathrm{~V}$ battery operates a water pump and other related electrical circuits that require only a $5 \mathrm{~V}$ voltage energy. Hence, wide storage for energy capacity ensures a smooth system operation and could last for a few days without any proper charging.

The following Figure 2 will display the process development of the PV system controlled by the switching PWM technique. The flow chart has shown that the phase PWM signal is controlled at distinct percentages for a better charging process for battery life extension. For that reason, the PWM charge controller consists of three charging modes.

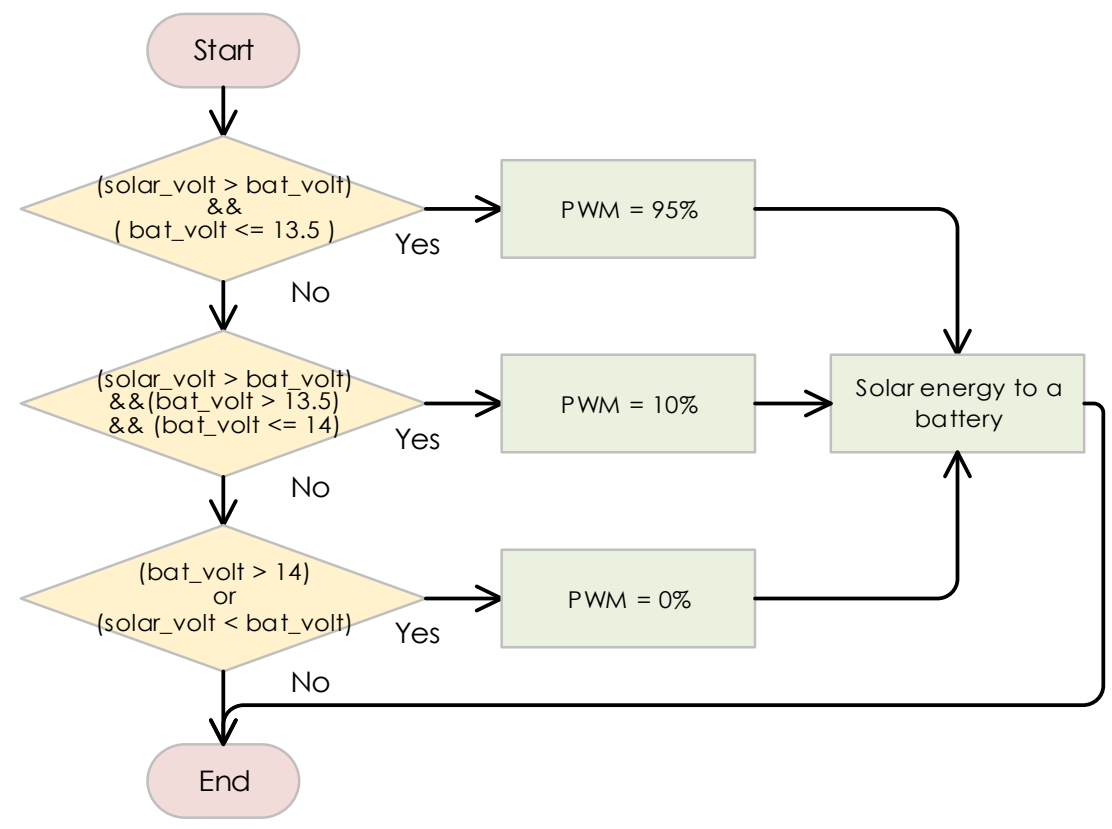

Figure 2. Percentage of PWM switching controller system for PV

From Figure 2, each mode was displayed with a different pulse width modulation percentage according to the respective condition. The NodeMCU ESP32 microcontroller will compare the obtained solar panel voltage and battery capacity voltage to determine the PWM ratio. The first condition is when the battery is less than $13.5 \mathrm{~V}$ while the solar panel voltage is more prominent than battery voltage thus the PWM ratio will be set to $95 \%$. The second condition happens if the battery voltage value is within $13.5 \mathrm{~V}$ to $14 \mathrm{~V}$ and the solar panel voltage is more considerable than battery voltage, the PWM ratio will be set to $10 \%$. The third situation is to turn off the PWM solar charge controller if the battery voltage value is more than $14 \mathrm{~V}$ or more significant than the solar panel voltage thus PWM ratio is defined as $0 \%$ level. This action can protect the battery condition from being overcharged, leading to a shorter life span.

Consequently, Figure 3 displayed the project equipment that has been implemented throughout the experiment consists of ESP32 microcontroller, BH1750 light sensor, DHT22 temperature, and humidity sensor, soil moisture sensor, water flow sensor, and $12 \mathrm{~V}$ water valve as shown in Figure 3(a) to Figure 3(f). During the experiment, some input sensors comprise of capacitive soil moisture sensors were applied to measure the water content present in the soil. Hence, the DHT22 sensor is used to measure the temperature and air humidity of the surrounding crops. Furthermore, the light sensor model BH1750 was instructed to collect their respective data every hour. As displayed in Figure 3, all the identified sensors are programmed using the ESP32 microcontroller around the SIS system.

An essential of the SIS system is the IoT support as data sensors collection will be an input for fuzzy logic membership determination which then controls the specific time and suitable quantity of water for irrigation operation. Thus, the IoT system implementation is presented using a block diagram of the process involved in Figure 4.

Bulletin of Electr Eng \& Inf, Vol. 11, No. 1, February 2022: 29-41 


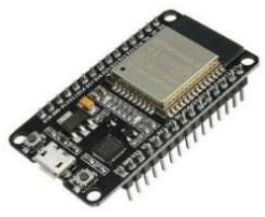

(a)

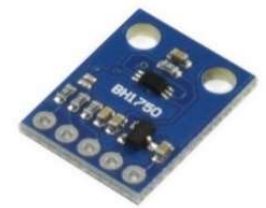

(d)

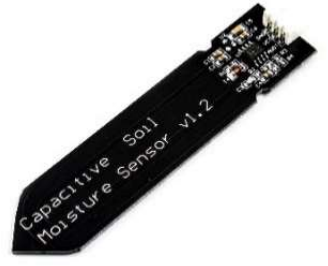

(b)

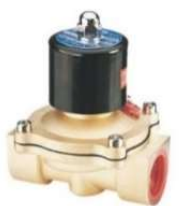

(e)

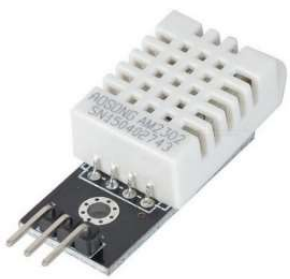

(c)

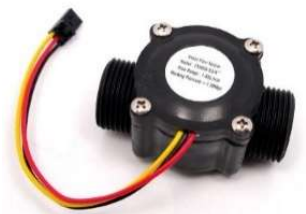

(f)

Figure 3. Project equipments (a) ESP32 microcontroller, (b) soil moisture sensor, (c) DHT22 temperature and humidity sensor, (d) BH1750 light sensor, (e) $12 \mathrm{~V}$ water valve, and (f) water flow sensor

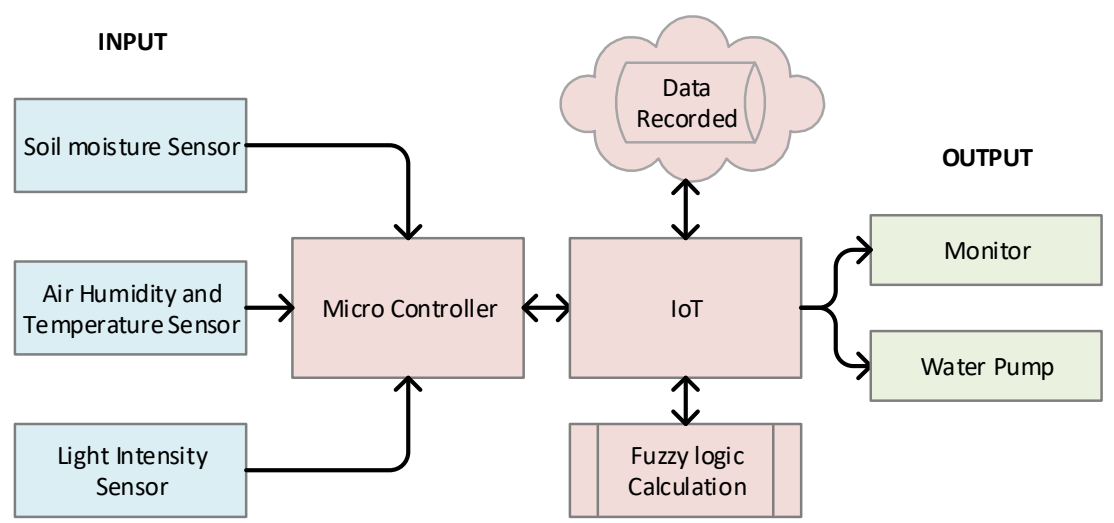

Figure 4. Block diagram of the SIS process

Fuzzy logic control that has been designed for irrigation on chili plants has a total of 5 parameters as shown from Table 1 to Table 5. In each parameter, they have their difference value of membership function. The membership function has represented the degree of truth of a logical control statement. The value in the membership function must be assigned manually for every single control parameter that comprises input and output signals. The 5 parameters are air humidity, temperature, soil moisture, irradiance and water pump duration. Four of the parameters are input signal and the water pump duration is the only output signal. The Fuzzy set input and output parameters are using trapezoidal membership functions [21]-[23]. For input parameter, 3 Fuzzy set is more than enough to differentiate the value range from overdose to insufficient level [24]. For that reason, the Table 1 is carried out to show the corresponding fuzzy set membership function range for soil moisture reading. While the irradiance reading is set according to the logic membership function is defined as dark, medium flux and light respectively as in Table 2.

Table 1. Soil moisture set range

\begin{tabular}{cc}
\hline \multicolumn{2}{c}{ Soil moisture factor } \\
Fuzzy set & Membership function \\
\hline Dry & {$[0,0,55,60]$} \\
Moist & {$[55,60,75,80]$} \\
Wet & {$[75,80,100,100]$} \\
\hline
\end{tabular}

Table 2. Irradiance set range

\begin{tabular}{cc}
\hline & $\begin{array}{c}\text { Irradiance factor } \\
\text { Fuzzy set }\end{array}$ \\
\hline Dark & {$[0,0,100,200]$} \\
Medium flux & {$[100,200,10000,11000]$} \\
Light & {$[10000,11000,65535,65535]$} \\
\hline
\end{tabular}


Another essential sensor called a temperature sensor is determined by the temperature setting range as displayed in Table 3. The appropriate humidity data range also influenced determining the most suitable water quantity to irrigate the chili plant to avoid evaporation, which can be referred to Table 4. Finally, the output which is water duration for action of irrigate to the chili plant are set as in Table 5 as the responded to the four identified input parameters setting. The corresponding membership function is determined using zero, very short, short, long and very long depend on their certain range.

Table 3. Temperature set range

\begin{tabular}{cc}
\hline \multicolumn{2}{c}{ Temperature factor } \\
Fuzzy set & Membership function \\
\hline Cold & {$[10,10,21,22]$} \\
Warm & {$[21,22,32,33]$} \\
Hot & {$[32,33,50,50]$} \\
\hline
\end{tabular}

Table 4. Humidity set range

\begin{tabular}{cc}
\hline \multicolumn{2}{c}{ Humidity factor } \\
Fuzzy set & Membership function \\
\hline Low & {$[0,0,60,65]$} \\
Medium humid & {$[60,65,70,75]$} \\
High & {$[70,75,99,99]$} \\
\hline
\end{tabular}

Table 5. Water duration set range

\begin{tabular}{cc}
\hline \multicolumn{2}{c}{ Watering duration factor } \\
Fuzzy set & Membership function \\
\hline Zero & {$[0,0,0,0]$} \\
Very short & {$[0300060009000]$} \\
Short & {$[6000,9000,12000,15000]$} \\
Long & {$[1200,1500,18000,21000]$} \\
Very long & {$[18000,2100,30000,30000]$} \\
\hline
\end{tabular}

In further, the fuzzy logic calculation will assign the appropriate duration needed for the watering action. The data obtained will then be recorded through the IoT support system, which is fuzzified by a fuzzy controller system. In the end, the fuzzy controller will decide the best suitable amount of water for irrigation to the chili plant. Besides the proper time for the water pump to operate simultaneously, the water flow volume has also been counted. The $2 \mathrm{~V}$ DC water pump utilizes the direct current to turn the solenoid valve and connect in series with the main water supply. The sensor model being used is the YFS-201 hall effect water flow sensor which is used to measure the flow rate and water volume being given to the crops. The minimum voltage for this flow sensor to be operated is $5 \mathrm{~V}$. The minimum water flow rate which this sensor can be detected is 1 liter per minute. Each data information will be sent to the Google Sheet form and stored within their column, respectively

Finally, the overall experiment setup for the SIS system is exhibited by photos as in Figures 5(a) and 5(b). The PV panel is controlled by the switching PWM technique that is depicted in Figure 5(a). The PWM signal is held at different percentages of the charging process for better battery life extension. All mentioned sensors are assembled at the suitable place of the chili plant in order to collect the vital data information for the irrigation system, as represented by Figure 5(b). The prototype of the soil area is $0.3 \mathrm{~m} \times 0.3 \mathrm{~m} \times 0.3 \mathrm{~m}$. During execution, the evaporation rate is referred from the area of Melaka evaporation reading which is $3 \mathrm{~mm}$ per day [25]. From the experiment, the preventive action that needs to take is to ensure the shadow from the chili plant does not reach the surface of the solar panel. Besides that, a thin layer of waterproof material is necessary to cover sensors' surface to prevent electronics from corroded.

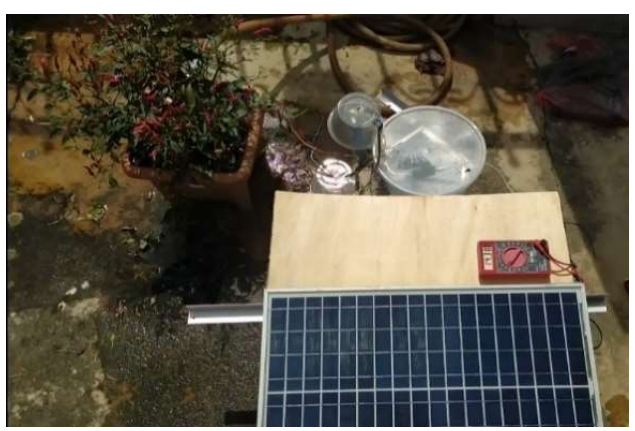

(a)

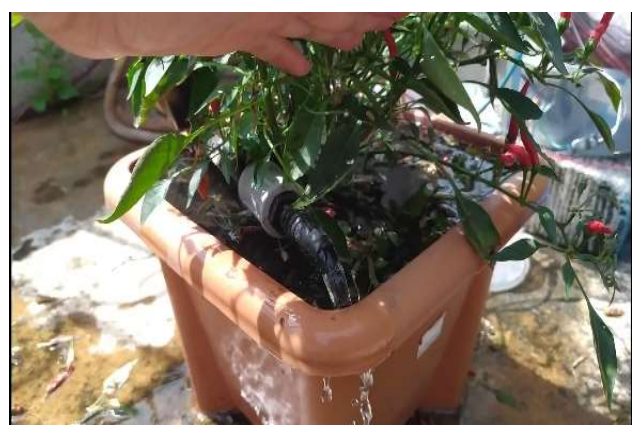

(b)

Figure 5. The SIS project development (a) PV panel, sensors and IoT hardware and (b) chili plant 


\section{RESULTS AND DISCUSSION}

This section will discuss the related results during the SIS development and the completion phase. The achievement is explained through the main processes involved in the experimental stages. The discussion will be on energy sustainability using the PV solar panel, the soil moisture measurement, fuzzy logic controller for membership determination, and the IoT support system for data collection performance as displayed through the google sheet form.

\subsection{PV solar sustainability}

The plotted graph in Figure 6 displayed sustained output energy to meet the load consumption at 0.55 Wh consistently. Thus, even though the input energy generated from the solar panel shows it fluctuated with respect to time, the power received is much higher than the demand (output energy).

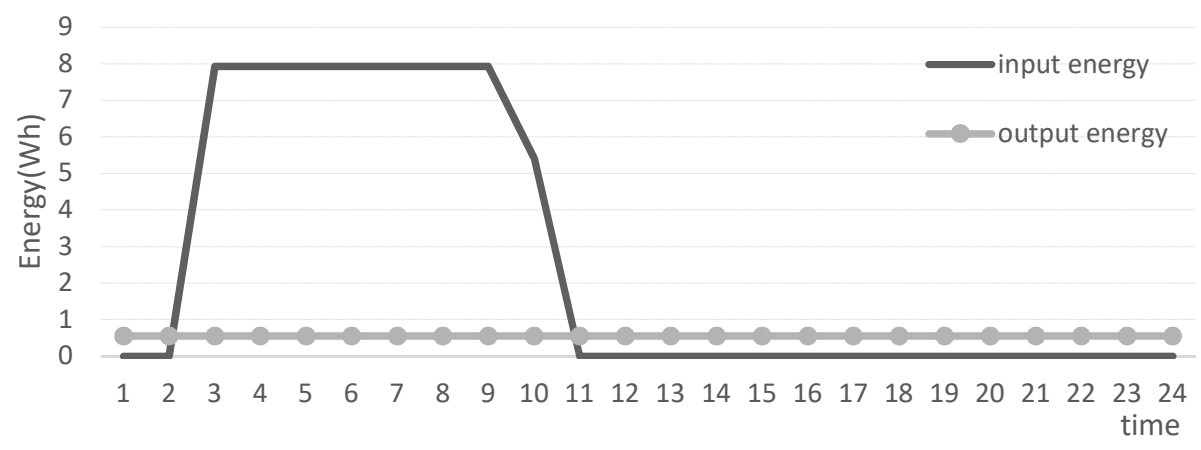

Figure 6. The graph for PV solar energy generated

The maximum input capability energy reached by the solar panel is about $61.07 \mathrm{Wh}$ per day by referring to the graph in Figure 6. The main reason for the varying power because of the block of clouds or shadows. The arrangement of thin-film solar within the PV solar module is series-connected. Thus, any possibility of shadow cover above accidentally will cause the generated current to decrease exponentially since an incremental internal resistance increases along the panel path.

Generally, the peak power demand is 1.2 Watt, but the provided energy is maintained as $0.55 \mathrm{Wh}$. The surge of load demand only occurred whenever the watering system microprocessor startup from the prolonging break cause the water solenoid valve to come into operation. Therefore, the total power consumption was 13.2 Wh per day on average. Meanwhile, battery charging is a complex process. The charging current becomes small when it is almost reaching its maximum power capacity, resulting in the solar energy not being absorbed fully.

\subsection{Soil moisture measurement}

Soil moisture is to descript the water content hold in the soil. Different types of soil will result in individual soil moisture due to the density, texture, precipitation, etc. The parameter used to determine the soil moisture is weight and the common approach is known as gravimetric soil water content. First, a soil sample is prepared where the weight is measured and recorded using a weighing scale, as portrayed in Figure 7. The soil sample was then be placed into an oven under a setting temperature of $105^{\circ} \mathrm{C}$. The high temperatures inside the oven are to dry out the soil faster.

As a result, the soil will lose its weight due to the evaporation of water content. Therefore, the process for the mass of the soil will proceed until the water content was evaporated completely so-called dry soil. Throughout the experiment, a weight for $209 \mathrm{~g}$ of the dry soil sample with the container weight at $18 \mathrm{~g}$ was prepared. Each test is handled using an additional $25 \mathrm{~g}$ of water increment before pouring into the dry soil. Then, the calculation for the soil moisture is measured using the formula in (1).

$$
\text { Soil moisture }=\frac{\text { wet soil weight }- \text { dry soil weight }}{\text { dry soil weigh }} \times 100 \%
$$




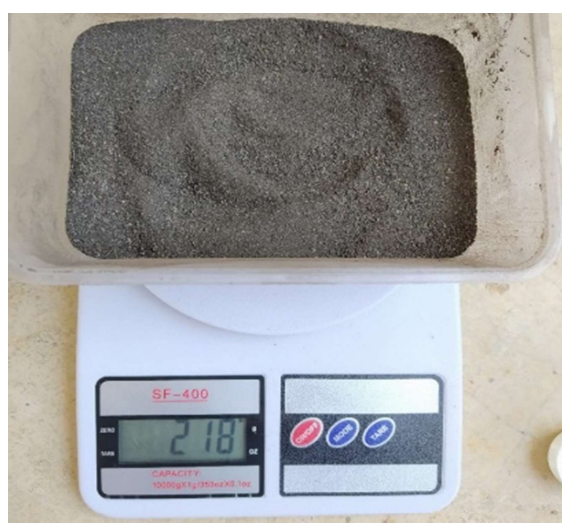

Figure 7. Dry soil measurement

For a particular test of soil moisture, the reading from the soil moisture sensor was recorded and analyzed as well as in Table 6 . From the results obtained, the soil moisture sensor analog display values showed a linear relationship trend as in Figure 8.

Table 6. Weight of soil measurement

\begin{tabular}{|c|c|c|c|c|c|c|c|}
\hline Item & $\begin{array}{l}\text { Mass of container }+ \\
\text { wet specimen, } M_{c w s} \\
(\mathrm{~g})\end{array}$ & $\begin{array}{l}\text { Mass of container }+ \\
\text { dried specimen, } M_{c s} \\
(\mathrm{~g})\end{array}$ & $\begin{array}{c}\text { Mass of } \\
\text { container, } \\
M_{c}(\mathrm{~g})\end{array}$ & $\begin{array}{l}\text { Mass of } \\
\text { water, } \\
M_{w}(\mathrm{~g})\end{array}$ & $\begin{array}{l}\text { Mass of solid } \\
\text { particle, } M_{s} \\
(\mathrm{~g})\end{array}$ & $\begin{array}{c}\text { Moisture } \\
\text { value, w } \\
(\%)\end{array}$ & $\begin{array}{l}\text { Soil moisture } \\
\text { sensor value }\end{array}$ \\
\hline Test 1 & - & 218 & 18 & 0 & 200 & $0 \%$ & 2927 \\
\hline Test 2 & 238 & 218 & 18 & 20 & 200 & $10 \%$ & 2100 \\
\hline Test 3 & 258 & 218 & 18 & 40 & 200 & $20 \%$ & 1735 \\
\hline Test 4 & 278 & 218 & 18 & 60 & 200 & $30 \%$ & 1600 \\
\hline Test 5 & 298 & 218 & 18 & 80 & 200 & $40 \%$ & 1350 \\
\hline Test 6 & 318 & 218 & 18 & 100 & 200 & $50 \%$ & 1250 \\
\hline Test 7 & 338 & 218 & 18 & 120 & 200 & $60 \%$ & 1180 \\
\hline Test 8 & 358 & 218 & 18 & 140 & 200 & $70 \%$ & 1160 \\
\hline Test 9 & 378 & 218 & 18 & 160 & 200 & $80 \%$ & 1150 \\
\hline Test 10 & 398 & 218 & 18 & 180 & 200 & $90 \%$ & 1120 \\
\hline Test 11 & 418 & 218 & 18 & 200 & 200 & $100 \%$ & 1100 \\
\hline
\end{tabular}

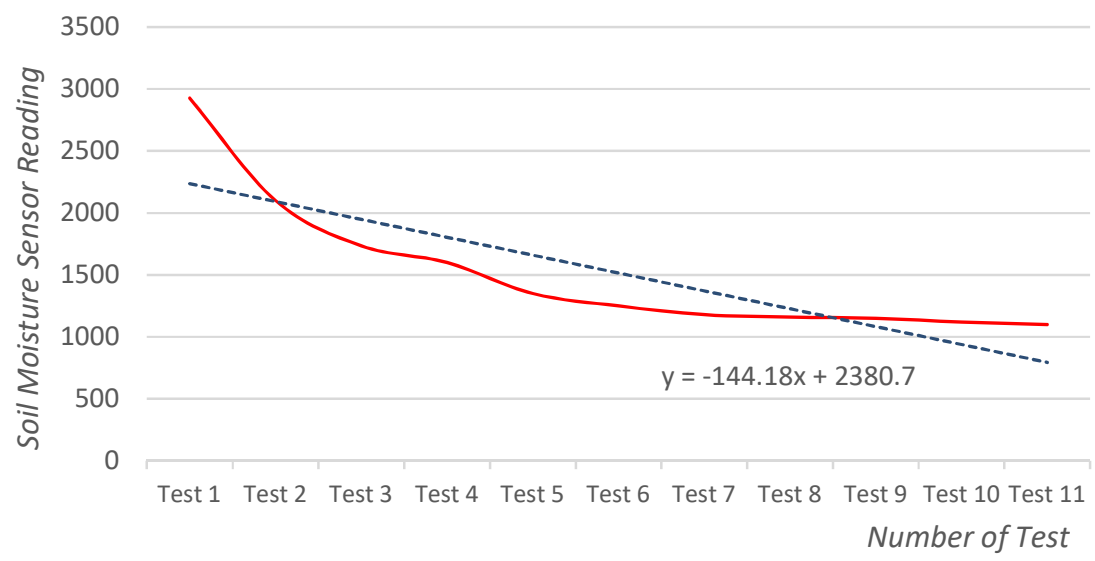

Figure 8 . The linear relationship of the soil moisture sensor reading

At beginning, the soil moisture sensor needs to be calibrated for the high precision result. From Figure 8, the soil moisture sensor showed a reduction in the response value when the soil moisture is getting high. In other words, the less varying sensor value occurs if soil moisture is almost closer to $100 \%$ maximum level. Even though the analog-digital converter of microprocessor ESP32 has 12 bits to support measurement 
value for the range of 0 to 4095, the soil moisture sensor failed to follow the processor range. Consequently, the soil moisture sensor implemented value range started from 2927 to 1100 in representing the soil moisture percentage from $0 \%$ to $100 \%$ for this research.

\section{THE LIGHT INTENSITY LEVEL}

Light level is the rate of sunlight shine on a surface and the unit is determined as the lumen. The BH1750 light sensor model is applied to measure illuminance which unit measurement used is lux. In the experiment, 1 unit lux is equivalent to one lumen per area for a square meter. Throughout the analysis, the chili plant is placed outdoor since the light intensity is an influencing factor to be investigated. An increment of light intensity will increase the surrounding temperature, which may lead the evapotranspiration rate of the plant to become higher than usual. Evapotranspiration is defined as the sum of water evaporation and transpiration from a surface that usually happens on the water surface or soil surface. For that reason, water losses through soil surface or plant leaves require replenishing. Therefore, the illuminance range was categorized based on typical conditions that generally occurred daily in Table 7. The conditions are identified as full daylight, overcast, partly cloudy, mostly cloudy, twilight and moonlight. The test result for full daylight is within the period from 10 a.m. to 5 p.m. exhibits light intensity, which is usually more than 10,000 lux. Based on the illuminance, it is not advised to irrigate the chili plant because it may cause evaporation before being absorbed by the root of the plant.

Table 7. Light level at different condition

\begin{tabular}{cc}
\hline Condition & Light Level (lux) \\
\hline Full daylight & $>10,000$ \\
Partially cloudy & 3,000 \\
Overcast & 1,000 \\
Twilight & 100 \\
Moonlight & $<15$ \\
\hline
\end{tabular}

Next, cloudy weather may happen any time of the day that contains a light intensity of around 3000lux. Occasionally, visible sunlight is high but the clouds are accidentally blocking the sunlight. It will cause the light intensity to be produced because the reflection from other places which is not affected by sunlight shading responded to the sensor. At this point, the light sensor module is not entirely covered by a black shadow. However, the light intensity level could be lower than the full daylight.

Another condition is called overcast weather, defined as the $95 \%$ visible area of the sky covered by clouds. However, clouds may become transparent, translucent, or opaque depending on the density of their water vapor. Therefore, the cloud could block a part of the sunlight to reach the surface chili plant. Usually, the overcast weather produced an illuminance value at around 1000 lux. While the condition of twilight is during dawn and dusk at two allocated times around 7 a.m to 8 a.m, and 6 p.m. to 7.00 p.m. The sensor reading showed weak illuminance and was recorded only at 100lux during both duration periods.

Finally, moonlight conditions are caused by the reflection of sunlight that comes from the moon's surface. Hence, the intensity of moonlight depends on the condition of the moon, which includes the new moon, full moon, first quarter, third quarter, etc. The intensity during full moon day intensity showed the highest value at around 15 lux. In contrast, on the new moon day, the light intensity has the lowest value of illuminance that reached 0lux. Since moonlight is during the period from 8 p.m, to 6 a.m., the intensity can be influenced by streetlights. The intensity of LED streetlights which are more substantial than moonlight may probably overlap moonlight. As a result, it will cause the light sensor module to capture light intensity results produced by streetlights.

\subsection{Fuzzy logic controller}

A fuzzy logic controller is essential to declare a vital membership function for five identified parameters involved in the SIS process. All the parameters are known as air humidity, temperature, soil moisture, irradiance, and water pump duration. Among them, four of the parameters are recognized as an input signal while the output signal was the duration of the water pump.

The prototype used for the soil area is $0.3 \mathrm{~m} \times 0.3 \mathrm{~m} \times 0.3 \mathrm{~m}$ with an evaporation rate of $3 \mathrm{~mm} /$ day. From mathematical formulation as represented in (2) thus a $2.7 \times 10^{-3} \mathrm{~m}^{3}$ water volume that is equivalent to 2.97 liters required for the system daily.

$$
\text { estimating evaporation rate }=\frac{3}{100} * 0.3 * 0.3
$$




$$
\text { estimating evaporation rate }=2.7 \times 10^{-3} \mathrm{~m}^{3} / \text { day }
$$

Thus, the water supply system was set at a one-liter flow rate per minute. The task was successfully done using an yfs-201 model as the water flow sensor. The response from the reading among all input sensors values is collected to proceed with the fuzzy logic controller task. The suitable membership function was decided during the fuzzifying phase. After the defuzzification process hence the corresponding input reading to result in the best suitable output is presented in Table 8 . In Table 8 , the increment of temperature will need a higher amount of water volume. In the comparison between day 1 until day 7 , there was some reduction in terms of the quantity of water volume. Mainly, a thorough analysis has shown that the temperature is high with less ambient illuminance was on day 7. The main reason for the factor is because of overcast weather with a nominal evapotranspiration rate. On the other hand, the recorded temperature was at maximum level on day 4, which has turned for more water volume for reirrigation as the water absorption and the evaporation rate is high.

In the main, the water volume irrigated to the chili plant results in the nearest to the evapotranspiration rate as calculated using (2). Therefore, it can be proved that the fuzzy logic Controller action precisely controls the water given and it has helped to replenish the water losses daily. Figure 9 describes all data captured through various kinds of sensors implemented.

Table 8 . The fuzzy memberships rules for input and output

\begin{tabular}{|c|c|c|c|c|c|c|}
\hline Time & $\begin{array}{c}\text { Condition of the } \\
\text { day }\end{array}$ & $\begin{array}{l}\text { Temperature } \\
\text { range }\left({ }^{\circ} \mathrm{C}\right)\end{array}$ & $\begin{array}{c}\text { Relative humidity } \\
\text { range }(\%)\end{array}$ & $\begin{array}{l}\text { Soil moisture } \\
\text { range }(\%)\end{array}$ & $\begin{array}{l}\text { Ambient light } \\
\text { range (lux) }\end{array}$ & $\begin{array}{l}\text { Water volume } \\
\text { (milliliter) }\end{array}$ \\
\hline Day 1 & Cloudy & $24.8-46.1$ & $40.3-99.9$ & $62-73$ & $10-43612$ & 2710 \\
\hline Day 2 & Full daylight & $25.8-49.2$ & $35.5-95$ & $52-82$ & $14.17-54612.5$ & 2878 \\
\hline Day 3 & Full daylight & $23.4-46.1$ & $43.8-99.9$ & $60-78$ & $12.5-54612.5$ & 2917 \\
\hline Day 4 & Full daylight & $24.6-49.6$ & $40.3-99.9$ & $63-66$ & $12.5-54612.5$ & 3210 \\
\hline Day 5 & Rainy & $26.4-48.8$ & 41.9-99.9 & $63-80$ & $12.5-54612.5$ & 2741 \\
\hline Day 6 & Cloudy & $24.9-43.1$ & $49.6-99.9$ & $63-70$ & $10-47570.83$ & 3046 \\
\hline Day 7 & Rainy & $27-40.2$ & $56.2-99.9$ & $62-84$ & $10-34612$ & 2550 \\
\hline
\end{tabular}

\begin{tabular}{|c|c|c|c|c|c|c|}
\hline Date & Time & temperature $\left({ }^{\circ} \mathrm{C}\right)$ & humidity(\%) & soil moisture(\%) & flux(lux) & water volume $(\mathrm{ml})$ \\
\hline $14 / 06 / 2021$ & $0: 35: 19$ & 28.1 & 90.3 & 70 & 14.17 & 175 \\
\hline $14 / 06 / 2021$ & $1: 35: 24$ & 27.9 & 90.9 & 70 & 14.17 & 177 \\
\hline $14 / 06 / 2021$ & $2: 35: 30$ & 27.6 & 91.4 & 68 & 14.17 & 175 \\
\hline $14 / 06 / 2021$ & $3: 35: 36$ & 26.9 & 92.6 & 69 & 14.17 & 174 \\
\hline $14 / 06 / 2021$ & $4: 35: 45$ & 26.4 & 93.7 & 64 & 14.17 & 174 \\
\hline $14 / 06 / 2021$ & $5: 35: 55$ & 26 & 94.3 & 63 & 14.17 & 174 \\
\hline $14 / 06 / 2021$ & $6: 36: 08$ & 26 & 94.3 & 58 & 14.17 & 174 \\
\hline $14 / 06 / 2021$ & $7: 36: 20$ & 25.8 & 95 & 56 & 1375.83 & 253 \\
\hline $14 / 06 / 2021$ & $8: 36: 47$ & 25.9 & 95 & 60 & 3817.5 & 175 \\
\hline $14 / 06 / 2021$ & $9: 37: 19$ & 27.7 & 91.6 & 64 & 5774.17 & 175 \\
\hline $14 / 06 / 2021$ & $10: 37: 32$ & 36.5 & 91.6 & 64 & 22341.8 & 0 \\
\hline $14 / 06 / 2021$ & $11: 36: 40$ & 42.9 & 73.4 & 63 & 53781 & 0 \\
\hline $14 / 06 / 2021$ & $12: 37: 19$ & 48.6 & 40 & 60 & 58342.3 & 0 \\
\hline $14 / 06 / 2021$ & $13: 37: 19$ & 47.3 & 42.1 & 52 & 56715.8 & 0 \\
\hline $14 / 06 / 2021$ & $14: 37: 19$ & 46 & 43 & 66 & 54387.5 & 0 \\
\hline $14 / 06 / 2021$ & $15: 37: 32$ & 45.4 & 40 & 68 & 42035.83 & 0 \\
\hline $14 / 06 / 2021$ & $16: 37: 33$ & 45.4 & 41.7 & 70 & 54612.5 & 0 \\
\hline $14 / 06 / 2021$ & $17: 37: 07$ & 49.2 & 35.5 & 70 & 13102.5 & 0 \\
\hline $14 / 06 / 2021$ & $18: 37: 40$ & 37.1 & 53 & 82 & 2478.33 & 0 \\
\hline $14 / 06 / 2021$ & $19: 37: 28$ & 33.4 & 66 & 72 & 1052.5 & 75 \\
\hline $14 / 06 / 2021$ & $20: 37: 25$ & 31.8 & 71.5 & 69 & 13.33 & 175 \\
\hline $14 / 06 / 2021$ & $21: 37: 30$ & 31.2 & 77.8 & 66 & 13.33 & 175 \\
\hline $14 / 06 / 2021$ & $22: 37: 35$ & 30.2 & 83.8 & 68 & 13.33 & 174 \\
\hline $14 / 06 / 2021$ & $23: 37: 38$ & 29.8 & 84.3 & 70 & 13.33 & 174 \\
\hline
\end{tabular}

Figure 9. Data record captured from database

Each data is updated each hour for a day. As a result, a total of 24 hours of data sets have been collected successfully throughout the experiment. The specific time of data taken was also stated clearly in the Google Sheet using the support of IoT system management. Based on the recorded data, the full daylight which in the period from 10 a.m. to 5 p.m. exhibits high light intensity that more than 10,000 lux. From the illuminance reading, it is not recommended to irrigate the chili plant since may cause for evaporation before being absorbed 
by the root of the plant. These crucial data are helpful to monitor the living condition of chili plants without walking into the field. In consequence, the human powering in the task of chili plants' irrigation would be greatly reduced. Besides that, a precaution in covering by layer up the sensors used in order to ensure it's always in good condition and able to function precisely.

\section{CONCLUSION}

This research is presented a solar system as the main supply to meet the demand of the SIS to be entirely operated. As known, solar energy usually is available in the daytime therefore the battery is responsible for acting as a backup during night operation. An experiment confirmed that battery operation could be sustained for more than three days with no charging. Meanwhile, the power generated from the solar modules is also much higher than the load demand for the entire system. Therefore, excessive power will be considered as battery storage for future use. Several vital sensors such as the BH1750 light sensor, DHT22 temperature and humidity sensor, and soil moisture sensor were recognized and implemented in giving the responses for inputs that will influence the output of the $12 \mathrm{~V}$ water valve as an action to the water flow sensor. The interaction of the operation of the overall sensors is mainly controlled by ESP32 microcontroller utilization. In addition, the SIS watering system is intelligently controlled using the fuzzy logic controller. This controller will decide the water amount to rinse the chili plant by implementing the membership function rules to utilize the water pump timing. The water flow rate has been fixed at a certain level; thus, the water amount output in a particular period will be consistent. Upon completion, the best suitable time for the chili plant irrigation successfully functioned automatically with the IoT support system. In conclusion, the SIS can be implemented on a large scale of crops as well as reduce the human power consumption for the irrigation process at the appropriate time. Furthermore, the evaporation reading obtained from the experiment is verified from the Melaka state evaporation data information.

\section{ACKNOWLEDGEMENTS}

The authors wish to acknowledge the Faculty of Electrical Engineering of Universiti Teknikal Malaysia Melaka in providing the laboratory equipment and components to assist the prototype development. We also thank Universiti Teknikal Malaysia Melaka (UTeM) and the Centre for Research and Innovation Management (CRIM) for successfully funding this research paper.

\section{REFERENCES}

[1] S. A. Hamoodi, A. N.Hamoodi, and G. M. Haydar, "Automated irrigation system based on soil moisture using arduino board," Bulletin of Electrical Engineering and Informatics, vol. 9, no. 3, pp. 870-876, Jun. 2020, doi: 10.11591/eei.v9i3.1736.

[2] M. A. M. Al-Obaidi, M. A. H. Radhi, R. S. Ibrahim, and T. Sutikno, "Technique smart control soil moisture system to watering plant based on IoT with arduino uno," Bulletin of Electrical Engineering and Informatics, vol. 9, no. 5, pp. 2038-2044, Oct. 2020, doi: $10.11591 /$ eei.v9i5.1896.

[3] S. N. A. Latif et al., "The Trend and Status of Energy Resources and Greenhouse Gas Emissions in the Malaysia Power Generation Mix," Energies, vol. 14, no. 8, p. 2200, Apr. 2021, doi: 10.3390/en14082200.

[4] M. M. Pujara, "SOLAR POWERED SMART IRRIGATION SYSTEM," International Journal of Advances in Agricultural Science and Technology, vol. 8, no. 3, pp. 48-56, Mar. 2021, doi: 10.47856/ijaast.2021.v08i3.005.

[5] A. I. Abdelkerim, M. M. R. S. Eusuf, M. J. E. Salami, A. Aibinu, and M. A. Eusuf, "Development of Solar Powered Irrigation System," IOP Conference Series: Materials Science and Engineering, vol. 53, p. 012005, Dec. 2013, doi: 10.1088/1757$899 \mathrm{X} / 53 / 1 / 012005$.

[6] M. H. Tushar, "Comparative study on DC-DC converters," BRAC University, 2012.

[7] C. A. Osaretin and E. O, "Design and implementation of a solar charge controller with variable output," Journal of electrical and electronic engineering, vol. 12, no. 2, pp. 40-50, 2015.

[8] R. T. A. Hamdi, S. Abdulhadi, H. A. Kazem, and M. Chaichan, "Humidity impact on photovoltaic cells performance: A review," International Journal of Recent Engineering Research and Development (IJRERD, vol. 3, no. 15, pp. 27-3, 2018.

[9] K. Rahimi, S. Mohajeryami, and A. Majzoobi, "Effects of photovoltaic systems on power quality," in 2016 North American Power Symposium (NAPS), Sep. 2016, pp. 1-6. doi: 10.1109/NAPS.2016.7747955.

[10] W. Anis and A. E.-S. El-Samahy, "A Microprocessor Based Load Voltage Regulator for Photovoltaic Systems.(Dept.E)," MEJ. Mansoura Engineering Journal, vol. 20, no. 1, pp. 32-44, Mar. 2021, doi: 10.21608/bfemu.2021.160157.

[11] J. Passioura, "Soil structure and plant growth," Soil Research, vol. 29, no. 6, p. 717, 1991, doi: 10.1071/SR9910717.

[12] G. Frisvold, C. Sanchez, N. Gollehon, S. Megdal, and P. Brown, "Evaluating Gravity-Flow Irrigation with Lessons from Yuma, Arizona, USA," Sustainability, vol. 10, no. 5, p. 1548, May 2018, doi: 10.3390/su10051548.

[13] M. E. and M. Mokhtar, "Irrigation: Types, Sources and Problems in Malaysia," in Irrigation Systems and Practices in Challenging Environments, InTech, 2012. doi: 10.5772/29710.

[14] A. M. Hassanli, M. A. Ebrahimizadeh, and S. Beecham, "The effects of irrigation methods with effluent and irrigation scheduling on water use efficiency and corn yields in an arid region," Agricultural Water Management, vol. 96, no. 1, pp. 93-99, Jan. 2009, doi: 10.1016/j.agwat.2008.07.004.

[15] A. H. Rizk and M. M. Sherif, "Effect of Soil Moisture Depletion on the Yield of Wheat under Sprinkler Irrigation at Toshka Area, Egypt," Middle East Journal of Agriculture Research, vol. 3, no. 4, pp. 981-987, 2014. 
[16] K. K. Patel and S. M. Patel, "Internet of Things-IOT: Definition, Characteristics, Architecture, Enabling Technologies, Application \& Future Challenges," International Journal of Engineering Science and Computing, vol. 6, no. 5, pp. 6122-6131, 2016, doi: $10.4010 / 2016.1482$

[17] M. Ayaz, M. Ammad-Uddin, Z. Sharif, A. Mansour, and E.-H. M. Aggoune, "Internet-of-Things (IoT)-Based Smart Agriculture: Toward Making the Fields Talk," IEEE Access, vol. 7, pp. 129551-129583, 2019, doi: 10.1109/ACCESS.2019.2932609.

[18] J. L. Hatfield and J. H. Prueger, "Temperature extremes: Effect on plant growth and development," Weather and Climate Extremes, vol. 10, pp. 4-10, Dec. 2015, doi: 10.1016/j.wace.2015.08.001.

[19] J. K. Williams, "Introduction to Fuzzy Logic," in Artificial Intelligence Methods in the Environmental Sciences, Dordrecht: Springer Netherlands, pp. 127-151. doi: 10.1007/978-1-4020-9119-3_6.

[20] K. Anand, C. Jayakumar, M. Muthu, and S. Amirneni, "Automatic drip irrigation system using fuzzy logic and mobile technology," in 2015 IEEE Technological Innovation in ICT for Agriculture and Rural Development (TIAR), Jul. 2015, pp. 54-58. doi: 10.1109/TIAR.2015.7358531.

[21] Alimuddin et al., "Monitoring System of Humidity Environmental on Chilli Red Green House Aeroponic System," 2021. doi: 10.2991/absr.k.210304.028.

[22] P. Alaboz, A. A. Işildar, M. Müjdeci, and H. Şenol, "Effects of different vermicompost and soil moisture levels on pepper (Capsicum annuum) grown and some soil properties," Yüzüncü Yll Üniversitesi Tarım Bilimleri Dergisi, vol. 27, no. 1, pp. 30-36, Mar. 2017, doi: $10.29133 /$ yyutbd.284217.

[23] M. G. Usman, M. Y. Rafii, M. R. Ismail, M. A. Malek, and M. Abdul Latif, "Heritability and Genetic Advance among Chili Pepper Genotypes for Heat Tolerance and Morphophysiological Characteristics," The Scientific World Journal, vol. 2014, pp. 1-14, 2014, doi: $10.1155 / 2014 / 308042$

[24] E. Cox, “Adaptive fuzzy systems," IEEE Spectrum, vol. 30, no. 2, pp. 27-31, Feb. 1993, doi: 10.1109/6.208359.

[25] M. Muhammad, M. Nashwan, S. Shahid, T. Ismail, Y. Song, and E.-S. Chung, "Evaluation of Empirical Reference Evapotranspiration Models Using Compromise Programming: A Case Study of Peninsular Malaysia," Sustainability, vol. 11, no. 16, p. 4267, Aug. 2019, doi: 10.3390/su11164267.

\section{BIOGRAPHIES OF AUTHORS}

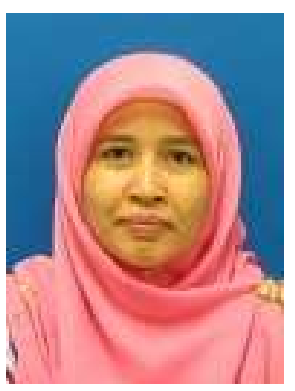

Elia Erwani Hassan (D) SC P is a Senior Lecturer at the Faculty of Electrical Engineering, Universiti Teknikal Malaysia Melaka. Begin in year 1995, using a Bachelor of Electrical Engineering qualification she started teaching experience as a lecturer in Universiti Teknologi Mara (UiTM), Shah Alam. She then completed her study in Universiti Teknologi Malaysia (UTM) in Master of Engineering Electrical-Mechatronics and Automatic Control. She did a Ph.D in Environmentally Constraint Economic Dispatch and Reactive Power Planning for Ensuring Secure Operation in Power System. Her research area is interested in power system and optimization. Ir. Dr. Elia Erwani Hassan also as a member of Board of Engineer Malaysia (BEM). She can be contacted at email: erwani@utem.edu.my.

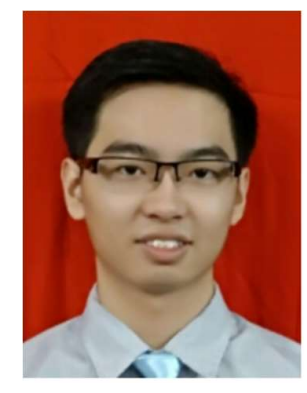

Leong Lek Chung (D) SC $\mathrm{P}$ was a final year student in B. Eng of Electrical Engineering in University Teknikal Malaysia Melaka. His final year project thesis is focused on the solar energy generation and agriculture IoT. Based on the learning experience thus he is aspiring to study in power system study. Now, Leong just recruited as an engineer and responsible in grid code test of solar power plant as one of his main field works. He can be contacted at email: b011710048@student.utem.edu.my.

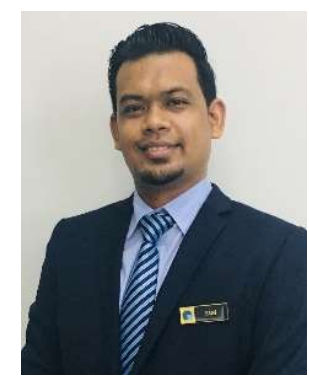

Mohamad Fani Sulaima (D) SC P is serving as Senior Lecturer in the Faculty of Electrical Engineering, Universiti Teknikal Malaysia Melaka (UTeM). Upon joining UTeM, he served as a Coordinator and Head for the Energy Management Division in the Centre for Sustainability and Environment before being appointed as the first internal University Energy Manager in 2015. He received his bachelor's degree from Tokai University, Japan, in 2010 and a Master's degree from the University of Malaya. He received Ph.D. in Electrical Engineering with a specialization in Energy Demand Side Management from Universiti Teknologi Mara (UiTM), Malaysia, in 2020. His research interests include power system, demand-side management, demand response, energy efficiency, measurement \& verification, and artificial intelligence. As a result of his research interest, he has published more than 90 articles, journals, and academic papers. He can be contacted at email: fani@utem.edu.my.

Bulletin of Electr Eng \& Inf, Vol. 11, No. 1, February 2022: 29-41 


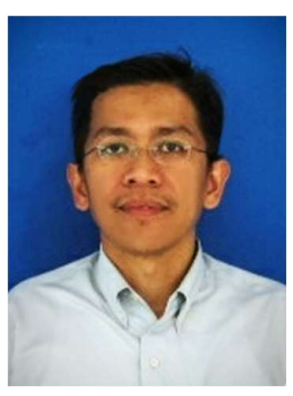

Nazrulazhar Bahaman (D) SC P is a Senior Lecturer at the Faculty of Information and Communication Technology, Universiti Teknikal Malaysia Melaka. With a Bachelor of Electrical Engineering qualification, he started gaining experience in networking sites as a Network Engineer. He has successfully developed his teaching skills at the Faculty of Electrical Engineering after graduating with a Master of Science in Information Technology. Qualified in both Electronic Engineering and Information Technology, he has brought together both disciplines in his Ph.D. concerning threats on IPV6 network. He can be contacted at email: nazrulazhar@utem.edu.my.

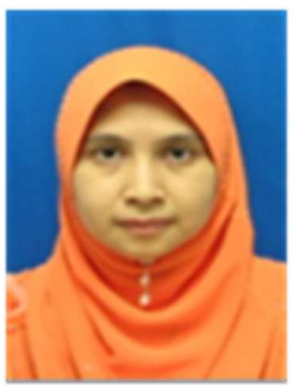

Aida Fazliana Bt. Abdul Kadir (D) SC P received a B.Eng in Electrical from Univ. Teknologi Malaysia in 2000, an M.Eng. degree in Electrical from Univ. Teknologi Malaysia, in 2003 and a Ph.D. in Electrical Engineering in the Universiti Kebangsaan Malaysia (UKM), Malaysia. She is currently a Senior Lecturer at the Department of Electrical Engineering, Universiti Teknikal Malaysia Melaka, Malaysia. Her research interests include power system and power quality, distributed generation and energy efficiency. Ir. Dr. Aida Fazliana is a registered member of the Board of Engineers, Malaysia (BEM) and member of the Institute of Engineering and Technology (IET,UK). She can be contacted at email fazliana@utem.edu.my. 